\title{
Flow Cytometric and Laser Scanning Microscopic Approaches in Epigenetics Research
}

\section{Lorant Szekvolgyi, Laszlo Imre, Doan Xuan Quang Minh, Eva Hegedus, Zsolt Bacso, and Gabor Szabo}

\begin{abstract}
Our understanding of epigenetics has been transformed in recent years by the advance of technological possibilities based primarily on a powerful tool, chromatin immunoprecipitation (ChIP). However, in many cases, the detection of epigenetic changes requires methods providing a high-throughput (HTP) platform. Cytometry has opened a novel approach for the quantitative measurement of molecules, including PCR products, anchored to appropriately addressed microbeads (Pataki et al. 2005. Cytometry $68,45-52)$. Here we show selected examples for the utility of two different cytometry-based platforms of epigenetic analysis: ChIP-on-beads, a flow-cytometric test of local histone modifications (Balint et al. 2005. Mol. Cell Biol. 25, 5648-5663), and the laser scanning cytometry-based measurement of global epigenetic modifications that might help predict clinical behavior in different pathological conditions. We anticipate that such alternative tools may shortly become indispensable in clinical practice, translating the systematic screening of epigenetic tags from basic research into routine diagnostics of HTP demand.
\end{abstract}

Key words: Chromatin immunoprecipitation (ChIP), flow cytometry, ChIP-on-beads, laser scanning cytometry (LSC).

\section{Introduction}

Epigenetic changes associated with gene regulation play a major role in the establishment of altered differentiation states (3). Specific modifications often correlate with gene activation or repression; for instance $\mathrm{H} 3 \mathrm{~K} 4 \mathrm{ac}$ and $\mathrm{H} 3 \mathrm{~K} 4 \mathrm{me} 3$ are permissive for gene activation whereas $\mathrm{H} 3 \mathrm{~K} 9 \mathrm{me} 2, \mathrm{H} 3 \mathrm{~K} 27 \mathrm{me} 3$, and methylation of $\mathrm{CpG}$ islands in promoter regions correlate with transcriptional silencing. Often, activating and repressive marks co-exist at gene start sites, reflecting perhaps epigenetic heterogeneity among otherwise similar cells, establishing a fine balance that could determine the gene expression patterns in the tissue. 
Szekvolgyi et al.

The 'epigenetic code' has become an indispensable concept in basic research, and its principles are also utilized to develop drugs and diagnostic tools. Several genes being epigenetically misregulated have been shown to associate with different kinds of cancer, highlighting the role of the 'language' of covalent modifications in tumorigenesis $(4,5)$. For instance, based on the patterns of modifications, two disease subtypes with different risks of tumor recurrence have been characterized in prostate cancer patients, independently from tumor stage, preoperative prostate-specific antigen levels, and capsule invasion (6).

The chromatin of cancer cells often exhibits both an overall (global) DNA hypomethylation and hypermethylation of specific regions, leading to 'DNA methylation imbalance' (7). The recurrence of global DNA hypomethylation in many types of human cancer is suggestive of its significant role in carcinogenesis, perhaps by inducing genomic instability and/or activating oncogenes $(8,9)$. However, global hypomethylation is subject to a high degree of variability, unaccounted for by our current level of understanding $(10,11)$. In addition to neoplastic transformation, problems of epigenetic regulation, including $\mathrm{CpG}$ methylation disorders are also involved in a wide range of pathological phenomena $(12,13)$. In most eukaryotes, methylation of DNA occurs at the cytosine residues of cytosine-phospho-guanine $(\mathrm{CpG})$ dinucleotides. The enzymes responsible for the production of 5-methylcytosine (5-mc) involving the fifth carbon atom of cytosine in $\mathrm{CpG}$ dinucleotides are the DNA methyltransferases DNMT1, DNMT3a, and DNMT3b, of which the first is involved in the maintenance of methylation during DNA replication, while all appear to be important in the establishment of methylation patterns in most physiological and pathological settings (14-16).

1.1. Flow- and Laser Scanning Cytometry in Epigenetics Research
Our understanding of epigenetics has been transformed in recent years by a succession of technological innovations. Approaches involving microarrays and, most recently ultra-high throughput (deep) sequencing technology have been applied to map cytosine methylation, chromatin modifications, and ncRNAs across entire genomes. Genome-scale studies of histone modifications and other aspects of chromatin structure typically rely on an immunological procedure, chromatin immunoprecipitation (ChIP) (17), in which specific antibodies are used to enrich chromatin. ChIP is a powerful tool in epigenetics; however, in many cases the detection of epigenetic changes or transcription factor binding associated with the regulation of certain genes would require ChIP-based methods that provide high-throughput (HTP) potential. Monitoring local as well as global changes of epigenetic markers could be extremely useful in diagnostics as well as in basic research.

Flow-cytometric analysis provides a novel means for the quantitative measurement of molecules also in cell-free solutions, anchoring them to appropriately addressed microbeads. The utility and power 
of this approach has been demonstrated in the case of various assays of molecular diagnostic value: immunoassays, sensitive measurement of protease or nuclease activity, detection of deletion/insertion of sequences by heteroduplex analysis, etc., that could all be adapted to a 'lab-on-beads' platform, i.e., the flow-cytometric analysis of microbead-captured macromolecules $(1,18,19)$. Many samples can be simultaneously analyzed in a FACSarray instrument using fluorescent dyes matching its optical channels.

Beyond lending a HTP platform for the analysis of genespecific epigenetic markers, cytometry also makes global analysis of epigenetic changes possible, most conveniently in its on-slide format, by microscope-based cytometers. Laser scanning cytometry (LSC) provides a robust method for analyzing single-cell events on slides $(20,21)$. It generates quantitative fluorescence data similar to flow cytometry, but the analyzed cells are attached to the surfaces of microscopic slides or culture chambers. The main advantages of LSC are that (i) the possible correlation between the simultaneously measured parameters is detected at the individual cell resolution, i.e., with a sensitivity surpassing that of flow cytometry; (ii) the instrument is able to relocate each cell for additional measurements, thus the analysis of functional features of live cells can be combined with measurements that require fixed cells; and (iii) measurements can be performed in an automated fashion, preprogrammed for several slides.

Examples highlighted in this review demonstrate the value of two different HTP platforms for epigenetic analysis, namely ChIPon-beads and assessment of global epigenetic traits by LSC. These methods might help introduce systematic screening of different epigenetic tags into clinical practice, especially of those that correlate with therapeutic success. It will be shown that sequencespecific capture of PCR-amplified ChIP-fragments on microbeads allows a robust detection of histone-tail modifications in the promoter region of a well-characterized gene, tissue transglutaminase type 2 (TGM2). We also assess the prospects of laser scanning cytometry for the analysis of epigenetic changes involving the whole genome via the example of a global DNA methylation test.

1.2. High-Throughput Screening of Local Epigenetic Changes by ChIP-on-Beads
We have investigated the cellular levels of $\mathrm{H} 4 \mathrm{~K}$ acetylation and H3K4 methylation of the histone tails at the promoter of the TGM2 gene, to test whether these covalent modifications can be detected using a flow-cytometric platform. As shown earlier (2)and briefly recapped herein, the flow-ChIP method, nicknamed ChIP-on-beads, can be easily implemented in a routine flow-cytometric clinical laboratory without relying on real-time QPCR. In the ChIP-on-beads assay, a standard ChIP is performed and then this DNA is used as template in an end-point PCR reaction. The sense and anti-sense primers are tagged at their $5^{\prime}$ ends with fluorescent dyes (e.g., Fam, Cy3) and biotin, 


\section{Szekvolgyi et al.}

respectively. Small aliquots of the Fam/biotin-ended PCR products are then bound to streptavidin-conjugated microbeads and quantified by flow cytometry. Of note, PCRs must be stopped in the linear phase to ensure reliable quantification; this should be initially determined in pilot QPCR experiments. The similarity of data obtained by QPCR and by flow cytometry has been shown (2).

As shown in Fig.7.1A, the fluorescence intensity of the microbeads increases linearly with the quantity of the fluoresceinated PCR products added, allowing the expression of ChIP-PCR

A

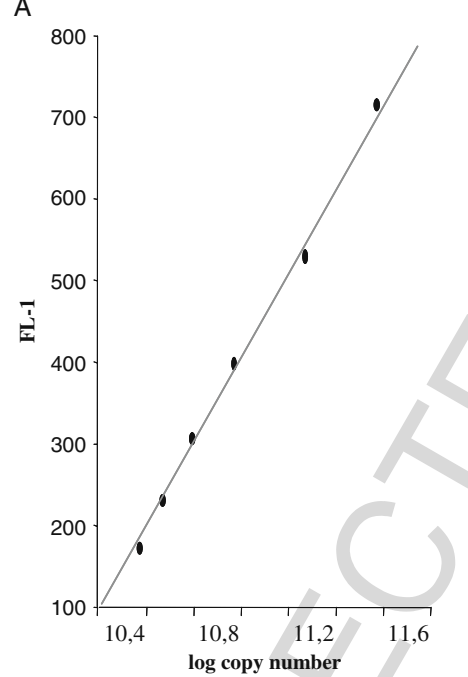

C

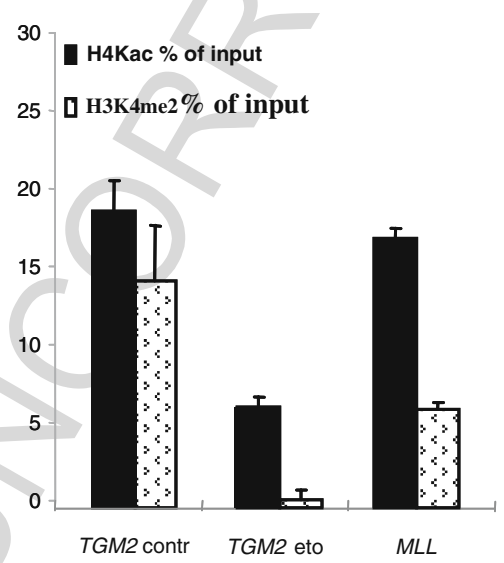

B

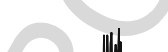

\footnotetext{
Fig. 7.1. Analysis of gene specific histone modifications by ChIP-on-beads. (A) Calibration curve (FL-1 vs. log copy number) based on a dilution series of known quantities of Fam/biotin-tagged PCR products. TGM2 copy numbers of ChIPPCR samples were determined by reference to this standard curve. (B,C) ChIP-on-beads analysis of H4Kac and H3K4me2 histone modifications at the TGM2 $\mathrm{g}$ ene promoter and at exon 9 of the $M L L$ gene, in Jurkat cells. Apoptosis was induced by etoposide treatment (Eto). (B) Flow-cytometric fluorescence distribution histograms of Fam/biotin-labeled ChIP-PCR samples captured on streptavidin-conjugated microbeads. (C) The level of modified histones within the TGM2 and MLL genes are expressed as percent of input values ( $Y$ axis), based on the means of fluorescence distribution and after subtracting the background (i.e., no-antibody \% of input values). Panels (B) and (C) were reproduced from (2).
} 


\subsection{Testing Global Epigenetic Changes by Laser Scanning Microscopy: Studies on DNA Methylation}

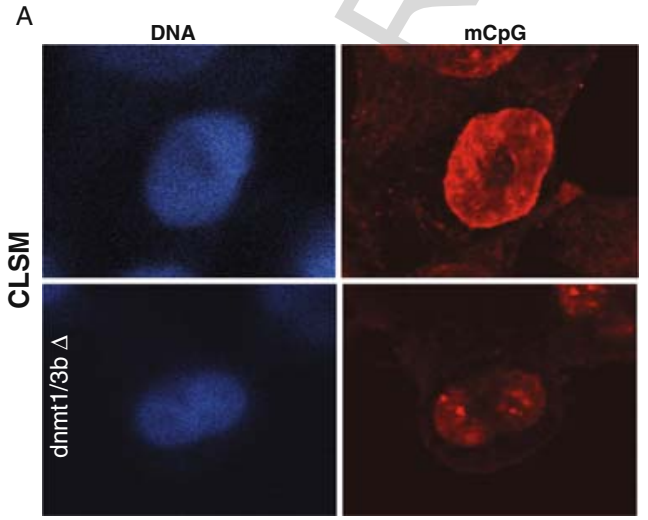

yields as absolute copy numbers. The flow-cytometric fluorescence distribution means are used to calculate the fraction of DNA copy numbers in the ChIP samples relative to the input DNA (Fig.7.1B). Comparing control and early-apoptotic Jurkat cells for changes in the level of $\mathrm{H} 4 \mathrm{Kac}$ and $\mathrm{H} 3 \mathrm{~K} 4$ me within the promoter of TGM2, we observed a significant decrease in both histone modifications (Fig.7.1C), suggestive of the closure of chromatin structure early upon apoptosis. In comparison, the observed histone modifications at exon 9 of the MLLgene, used as positive control, were in accordance with its known histone-code profile (22); in contrast, the $\beta$-globin gene, used as negative control, gave $<0.1 \% \mathrm{Ab} /$ input ratios (not shown).

It is often important to consider in what global context local epigenetic changes occur (23). Moreover, global changes of certain epigenetic modifications may have their independent diagnostic value, especially when analyzed in correlation with other phenotypic markers, an opportunity offered by up-to-date laser scanning microscopic systems $(20,21)$. Development of antibodies and chimeric methyl CpG-binding antibody-like proteins (24-27), both recognizing CpG with high specificity, has opened novel perspectives for the diagnostic analysis of global methylation states. Anti-5mC antibodies are commercially available through various sources (e.g., Abcam and Biocarta US).

In experiments using the recombinant $\mathrm{mCpG}$-binding antibody-like MBD-Fc protein (26-28), the overall level of CpG methylation has been quantified in the HCT116 cell line (Fig.7.2). As shown by confocal laser scanning microscopy

Fig. 7.2. Global DNA methylation analyzed by confocal laser scanning microscopy and laser scanning cytometry. WT: wildtype DNMT1/DNMT3b HCT116 cells immunolabeled with the MBD-Fc fusion protein. K.0.: dnmt1/dnmt3b knock-out HCT116 cells immunolabeled with the MBD-Fc fusion protein. Left slides: DNA stained by Hoechst. Right slides: methylated DNA (mCpGs). (A) Methylated CpG dinucleotides visualized by confocal laser scanning microscopy (CLSM). (B) Sample analyzed by laser scanning cytometry (LSC). MCpG (red) fluorescence was quantified in the slide-attached cells $(n>400)$ and presented (in arbitrary units) as fluorescence distribution histograms. 
Szekvolgyi et al.

(CLSM), mCpGs have been efficiently labeled by indirect immunofluorescence in $D N M T l / 3 b$ wild-type and, to a lesser extent, DNATT/3b double knock-out cells. The level of $\mathrm{mCpGs}$ has been quantified in a sizable population of cells by an iCys laser scanning cytometer and iCyte 2.6 software (CompuCyte, USA). As shown in Fig.7.2, the fluorescence distributions of the Alexa546-labeled mCpGs are significantly different in the $D N M T I / 3 b^{+/-}$cells; this result demonstrates the utility of LSC for the fine assessment of global methylation states in different cell types (e.g., differentiated vs. stem cells) or in a specific cell type (e.g., in human peripheral lymphocytes isolated from blood samples) before and after drug treatment or chemotherapy. Since LSC can be performed in an automated fashion, such studies could be made on large sets of biopsy material so as to establish the exact role of global DNA methylation in human pathological diagnosis of various diseases.

Data presented herein have demonstrated that if combined, flow cytometry and conventional PCR offer a powerful tool in the quantitative analysis of ChIP results. We have found high levels of H4Kac and H3K4me at the TGM2gene core promoter (Fig.7.1). These levels significantly decreased upon apoptosis and this was accompanied by the down-regulation of TGM 2 mRNA expression (2), suggesting that this enzyme does not contribute to the early manifestations of apoptosis in Jurkat cells. Differences in the global level of DNA methylation in HCT1 16 wild-type and methylation defective cells have been revealed by LSC, the on-slide version of flow cytometry (Fig.7.2). Both assays can be easily implemented, and readily applied in a HTP format. We envisage the utility of these platforms primarily in clinical screening efforts addressing one, or a few, epigenetic markers in many samples simultaneously, depending on cost/time considerations and availability of instrumentation/expertise.

Although the epigenetic changes are heritable, they appear to be readily reversed by specific drug treatments as opposed to gene mutations. We expect that the epigenetic silencing of, e.g., tumor suppressor genes will soon become a frequent target of HTP screening studies because these mechanisms may be as important in carcinogenesis as the inactivating mutations. Drugs targeting the enzymes that remove or add these chemical tags are at the forefront of research: diseases to be targeted include cancer, imprinting disorders, autoimmune diseases, certain neurological disorders, diabetes, cardiopulmonary diseases, in which mis-steps in epigenetic programming have been directly implicated. Pharmaceutical companies have set up programs on histone decacetylases (HDACs) and DNA methyltransferases (DNMTs) and their inhibitors, as they have the potential to re-activate specific tumor suppressor genes; clinical trials being on the way are promising the prospect of eliciting tumor regression by modulation of epigenetic regulation. 
Based on the above, we anticipate that epigenetic analysis will enter routine diagnostic practice whenever monitoring epigenetic markers can help predict clinical behavior. When large sets of samples are to be assessed, high-throughput platforms for the accurate evaluation of the ChIP results are of general interest. In view of the fact that most routine techniques can be adapted to flow cytometry which exceeds more conventional methods in sensitivity and reproducibility, the approaches shown can provide a universal platform for almost any kind of lab purposes. Whether ChIP-QPCR, ChIP-on-beads, or LSC-based assays of global epigenetic changes will be selected as the approach of choice for such screening projects will be determined by the particular task undertaken, and the capabilities of the clinical laboratories. We believe that these alternative ChIP platforms can help bring epigenetic analysis within reach for routine laboratories, especially for those involved in clinical diagnostics.

\section{Materials}

\subsection{Cell Culture}

2.2. Detection of Methylated CpGs by Immunofluorescence
1. McCoy's medium (Sigma-Aldrich).

2. Solution of trypsin: stock solution at $0.5 \%$, working solution at $0.05 \%$ in $1 \mathrm{X}$ phosphate buffered saline $(\mathrm{PBS})$; store at $20^{\circ} \mathrm{C}$.

3. Glutamine: stock solution at $200 \mathrm{mM}$, final concentration at 2 $\mathrm{mM}$ in $\mathrm{ddH}_{2} \mathrm{O}$; store at $-20^{\circ} \mathrm{C}$.

4. Etoposide (Sigma-Aldrich): stock solution at $40 \mathrm{~m} M$, working concentration at $40 \mu \mathrm{M}$.

1. IX PBS: $1.37 \mathrm{MNaCl}, 27 \mathrm{~m} M \mathrm{KCl}, 100 \mathrm{~m} M \mathrm{Na}_{2} \mathrm{HPO}_{4}, 18$ $\mathrm{m} M \mathrm{KH}_{2} \mathrm{PO}_{4}$; adjust to $\mathrm{pH} 7.4$ with $\mathrm{HCl}$ if necessary.

2. Labeling solution: $1 \mathrm{X} \mathrm{PBS} / 10 \% \mathrm{BSA}$; store at $-20^{\circ} \mathrm{C}$.

3. Primary antibody $(1.9 \mathrm{mg} / \mathrm{mL})$ : MBD-Fc, a recombinant antibody which was made of human MBD domain (methyl binding domain) fused with an Fc fragment of a human IgGl and expressed in Drosophila S2 cells (26-28); store at $4^{\circ} \mathrm{C}$.

4. Secondary antibody $(2 \mathrm{mg} / \mathrm{mL})$ : Alexa546-conjugated antihuman IgG (Invitrogen); store at $4^{\circ} \mathrm{C}$.

5. Hoechst 33342 (Invitrogen): stock solution: $1 \mathrm{~m} M$, working solution: $4 \mu M$, final concentration: $2 \mu M$, diluted in IX PBS; store at $-20^{\circ} \mathrm{C}$.

6. Prolong Gold (Invitrogen). 
Szekvolgyi et al.

\subsection{ChIP-on-Beads}

1. Nucleus isolation buffer: $5 \mathrm{~m} M$ pipes, $\mathrm{pH} 8.0,85 \mathrm{mMKCl}$, $0.5 \% \mathrm{NP}-40$, protease inhibitors (Sigma-Aldrich, cat no. P8340).

2. Sonication buffer: 1\% SDS, $10 \mathrm{~m} M$ EDTA, $50 \mathrm{~m} M$ Tris- $\mathrm{HCl}$, $\mathrm{pH} 8.0$, protease inhibitors.

3. IP buffer: $0.01 \%$ SDS, $1.1 \%$ Triton X-100, 1.2 mMEDTA, 20 $\mathrm{m} M$ Tris- $\mathrm{HCl} \mathrm{pH} 8.0,167 \mathrm{mMNaCl}$, protease inhibitors.

4. Blocked protein A/G Sepharose (Upstate, cat. no. 16-157).

5. Antibodies (Upstate): anti-H4Kac, $2 \mu \mathrm{g} / \mathrm{IP}$ (cat. no. 06866), anti-H3K4me2, $5 \mu \mathrm{g} / \mathrm{IP}$ (cat. no. 07-030).

6. Wash buffer (WB) A: $0.1 \%$ SDS, 1\% Triton X-100, $2 \mathrm{mM}$ EDTA, $20 \mathrm{~m} M$ Tris- $\mathrm{HCl}, \mathrm{pH} 8.0,150 \mathrm{mMNaCl}$, protease inhibitors.

7. WB B: $0.1 \%$ SDS, $1 \%$ Triton X-100, 2 mMEDTA, 20 $\mathrm{m} M$ Tris- $\mathrm{HCl}, \mathrm{pH} 8.0,500 \mathrm{~m} M \mathrm{NaCl}$, protease inhibitors.

8. WB C: $0.25 \mathrm{MLiCl}, 1 \% \mathrm{NP}-40,1 \% \mathrm{Na}$-deoxycholate, 1 $\mathrm{m} M$ EDTA, $10 \mathrm{~m} M$ Tris- $\mathrm{HCl}, \mathrm{pH} 8.0$, protease inhibitors.

9. IX TE: 10 mMTris- $\mathrm{HCl}, \mathrm{pH} 7.5,1$ mMEDTA.

10. QIAquick PCR Purification Kit (Qiagen).

11. Primers: forward 5'-Fam-GAGACCCTCCAAGTGCGAC-3', reverse 5'-Biotin-CCAAAGCGGGCTATAAGTTA GC-3'.

12. Streptavidin-coated microbeads ( $6 \mu \mathrm{m}$, Polyscience).

\section{Methods}

\subsection{ChIP-on-Beads}

1. Treat exponentially growing Jurkat cells with $40 \mu$ Metoposide (eto) for $3 \mathrm{~h}$ at $37^{\circ} \mathrm{C}$ to induce apoptosis.

2 . Fix cells with $1 \%$ formaldehyde for $10 \mathrm{~min}$ at room temperature. Stop fixation by adding $2.5 \mathrm{M}$ glycine to a final concentration of $0.67 M$, for $5 \mathrm{~min}$ at room temperature. Wash cells twice in ice-cold PBS.

3. Resuspend cells in $1 \mathrm{~mL}$ of nucleus isolation buffer and incubate them for $10 \mathrm{~min}$ on ice. Vortex tubes in every 2-3 $\mathrm{min}$.

4. Centrifuge isolated nuclei at $500 \mathrm{~g}$ for $3 \mathrm{~min}$, at $4^{\circ} \mathrm{C}$. Resuspend pellet in $500 \mu \mathrm{L}$ sonication buffer.

5. Sonicate chromatin to an average fragment size of $500 \mathrm{bp}$ using a Bioruptor (Diagenode); $0.5 \mathrm{~min} \mathrm{ON} / 0.5 \mathrm{~min} \mathrm{OFF}$ pulses for $2 \times 12 \mathrm{~min}$ usually produces the desired size distribution. 
6. Centrifuge sheared chromatin samples at maximum speed for $20 \mathrm{~min}$. Keep supernatants (leave $50 \mu \mathrm{L}$ on the bottom of the tubes). Freeze in liquid nitrogen and store samples at $-80^{\circ} \mathrm{C}$ (or proceed immediately).

7. Thaw samples on ice and centrifuge them at maximum speed for $10 \mathrm{~min}$ at $4^{\circ} \mathrm{C}$. Transfer supernatants into clean tubes (do not disturb pellet on the bottom of the tubes).

8. Dilute chromatin samples 1:10 in IP buffer as follows: $100 \mu \mathrm{L}$ chromatin $900 \mu \mathrm{L}$ IP buffer.

9. Pre-clear samples by incubating them on a rotating wheel with $30 \mu \mathrm{L}$ of blocked protein $\mathrm{A} / \mathrm{G}$ Sepharose for $30 \mathrm{~min}$ at $4^{\circ} \mathrm{C}$. Spin samples at $500 \mathrm{~g}$ for $3 \mathrm{~min}$ at $4^{\circ} \mathrm{C}$. Keep supernatants.

10. Perform immunoselection for $>12 \mathrm{~h}$ on a rotating wheel by adding the following antibodies to the samples: anti-H4Kac and anti-H3K4me2; as negative control, omit specific Ab but add a specific IgG protein from the same isotype to one of the pre-cleared samples.

11. Preserve $10 \mu \mathrm{L}$ from the 'negative control' as 'input' DNA and store it at $-20^{\circ} \mathrm{C}$. Collect immune complexes by adding $40 \mu \mathrm{L}$ of blocked protein A/G Sepharose to each sample and incubate them for $45 \mathrm{~min}$ on a rotator. Spin samples at $500 \mathrm{~g}$ for $3 \mathrm{~min}$.

12. Wash the pelleted immune complexes as follows: $2 \times \mathrm{WB}$ A, $2 \times \mathrm{WB}$ B, $2 \times \mathrm{WB}$ C, $1 \times$ TE. Resuspend pellets in $500 \mu \mathrm{L}$ TE. At this point thaw input DNA and dilute it to $500 \mu \mathrm{L}$; process it together with the IP samples.

13. Reverse cross-links by incubating the samples at $98^{\circ} \mathrm{C}$ for $10 \mathrm{~min}$. Put samples on ice.

14. Digest residual RNAs with $200 \mu \mathrm{g} / \mathrm{mL}$ RNase A for $30 \mathrm{~min}$ at $37^{\circ} \mathrm{C}$.

15. Digest proteins by $0.5 \mathrm{mg} / \mathrm{mL}$ proteinase $\mathrm{K}$ for at least $2 \mathrm{~h}$ at $55^{\circ} \mathrm{C}$.

16. Purify DNA on PCR clean-up columns (Qiagen). Immunoprecipitated DNA samples (input, negative control, H4Kac/ H3K4me2, respectively) are ready to be tagged by Fam/ biotin PCR.

17. In the Fam/biotin PCR, use primers listed in Section2.3. Perform PCRs under standard conditions and stop after 15-20 cycles, i.e., in the linear phase. Validate by QPCR (2). Purify the $5^{\prime}$-Fam/biotin labeled ChIP-PCR products on PCR clean-up columns.

18. Carry out flow cytometry on a Becton-Dickinson FACScan flow cytometer as follows: $5 \mu \mathrm{L}$ of the Fam/biotin-tagged ChIP-DNA was added to 10,000 streptavidin-coated, plain 
Szekvolgyi et al.

beads in $50 \mu \mathrm{L}$ PBS. Incubate samples for $15 \mathrm{~min}$ at room temperature, wash in $1 \mathrm{~mL} \mathrm{PBS}$, and run at high speed. Set laser power to $15 \mathrm{~mW}$ and detect fluorescence signals through the 530/30 interference filter of the FLl channel in logarithmic mode. Evaluate results using the BDIS CELLQUEST 3.3 (Becton-Dickinson) software. TGM2 copy numbers are determined by reference to a standard curve obtained from a dilution series of known quantities of Fam/biotin-tagged PCR products (Fig.7.1A). Express ChIP yields as percentage of input after subtracting background (no antibody (nAb) \% of input).

\section{2.}

Immunofluorescence and Laser Scanning Cytometry
1. Grow HCT116 DNMTI/3b wt and DNMTI/3b knock-out cells on coverslips overnight.

2. Wash cells in $200 \mu \mathrm{L}$ IX PBS, $3 \times 3 \mathrm{~min}$.

3. Fix cells in a series of diluted methylalcohol (MetOH) (as shown below); wash cells with $200 \mu \mathrm{L}$ of diluted $\mathrm{MetOH}$ once for $3 \mathrm{~min}$, for each dilution. Start with the $10 \times$ dilution. After washes, incubate cells in concentrated $\mathrm{MetOH}$ overnight at $-20^{\circ} \mathrm{C}$.

\begin{tabular}{|lll} 
& 1X PBS $(\mu \mathrm{L})$ & MetOH $(\mu \mathrm{L})$ \\
\hline $10 \times \mathrm{MetOH}$ & 900 & 100 \\
\hline $8 \times \mathrm{MetOH}$ & 875 & 125 \\
\hline $6 \times \mathrm{MetOH}$ & 833 & 167 \\
\hline $4 \times \mathrm{MetOH}$ & 750 & 250 \\
\hline $2 \times \mathrm{MetOH}$ & 500 & 500 \\
\hline
\end{tabular}

4. Rehydrate cells in a series of diluted IX PBS as shown below; wash cells in $200 \mu \mathrm{L}$ diluted $\mathrm{MetOH}$ for $3 \mathrm{~min}$ in each dilution. Start with the $10 \times$ dilution. After the final rehydration step, wash with $200 \mu \mathrm{L} 1 \mathrm{X}$ PBSs

MetOH $(\mu \mathrm{L})$

1X PBS $(\mu \mathrm{L})$

\begin{tabular}{|ccc}
\hline $10 \times(1 \mathrm{X} P B S)$ & 900 & 100 \\
\hline $8 \times(1 \mathrm{X} P B S)$ & 875 & 125 \\
\hline $6 \times(1 \mathrm{X} P B S)$ & 833 & 167 \\
\hline $4 \times(1 \mathrm{X} P B S)$ & 750 & 250 \\
\hline $2 \times(1 \mathrm{X} P B S)$ & 500 & 500 \\
\hline
\end{tabular}


5. In order to relax DNA, place samples into Petri dishes (without the cover) in PBS/1\% BSA and irradiate them with UV light for $30 \mathrm{~min}$.

6. Immunolabel samples using the mCpG-specific MBD-Fc fusion protein or a commercially available Anti- $5 \mathrm{mC}$ as primary antibody for $30 \mathrm{~min}$ at room temperature. Wash cells in $200 \mu \mathrm{L}$ of $1 \% \mathrm{BSA} / \mathrm{PBS}, 3 \times$ for $3 \mathrm{~min}$.

7. Label samples with an Alexa546-conjugated anti-human IgG secondary antibody, for $30 \mathrm{~min}$ at room temperature. Wash cells in $200 \mu \mathrm{L} \mathrm{l} \%$ BSA/PBS $3 \times$ for $3 \mathrm{~min}$.

8. Stain DNA with $50 \mu \mathrm{L}$ Hoechst $33342(2 \mu M)$ and cover with Prolong Gold antifade.

9. Scan slides (see Note 1).

\section{Notes}

1. MCpGs have been visualized using a Zeiss LSM 510 confocal laser-scanning microscope using excitation wavelengths of 543 and $351 / 364 \mathrm{~nm}$. Fluorescence emission was detected through 560-615 and 385-470 nm band-pass filters. Images were taken in multitrack mode to prevent cross-talk between the channels. Pixel image $(512 \times 512)$ stacks of $2-2.5 \mu \mathrm{m}$ thick optical sections were obtained with a $63 \times$ PlanApochromat oil immersion objective (NA 1.4).

The same samples were also analyzed using an iCys laser scanning cytometer (CompuCyte). The instrument used in our studies is equipped with a violet-blue diode, an argon-ion, and a $\mathrm{HeNe}$ laser (wavelengths 405, 488, and $633 \mathrm{~nm}$, respectively). The violet and Ar-ion laser lines were used for excitation of Hoechst and Alexa 546 dyes. To identify single nuclei, contouring was based on Hoechst fluorescence detected in the blue channel $(460-485 \mathrm{~nm})$. Fluorescence of Alexa 546 (MCpGs) was detected in the orange channel (565-585 nm) based on the contour gained in the blue channel. In single nuclei identified by contouring on fluorescence of the nuclear stain, the integral fluorescence related to the MCpGs divided by the area of the contour was used to describe the methylation level. This corrects for differences in nuclear size. Data evaluation and hardware control were performed using the iCys 2.6 software for Windows XP. Using the $4 \times$ objective to scan an indicated area on a slide, 400-1000 cells were scanned in about $10 \mathrm{~min}$ (21). LSC can screen relatively large number of cells on a slide. The cells are distinguished 
Szekvolgyi et al.

based on their fluorescence properties like in flow cytometry. However, as the position of each cell is fixed on the slide and the instrument saves the positional information, any correlation between the different parameters measured can be detected in a very sensitive manner. In addition, the cells can be relocated and visually analyzed or re-scanned after re-staining with conventional stains or fluorescent markers.

\section{Acknowledgments}

\section{References}

1. Pataki, J., Szabo, M., Lantos, E., Szekvolgyi, L., Molnar, M., Hegedus, E., Bacso, Z., Kappelmayer, J., Lustyik, G. and Szabo, G. (2005) Biological microbeads for flowcytometric immunoassays, enzyme titrations, and quantitative PCR. Cytometry $68,45-52$.

2. Szekvolgyi, L., Balint, B. L., Imre, L., Goda, K., Szabo, M., Nagy, L. and Szabo, G. (2006) Chip-on-beads: flow-cytometric evaluation of chromatin immunoprecipitation. Cytometry 69, 1086-1091.

3. Balint, B. L., Szanto, A., Madi, A., Bauer, U. M., Gabor, P., Benko, S., Puskas, L. G., Davies, P. J. and Nagy, L. (2005) Arginine methylation provides epigenetic transcription memory for retinoid-induced differentiation in myeloid cells. Mol. Cell Biol. 25, 5648-5663.

4. Downs, J. A. and Jackson, S. P. (2003) Cancer: protective packaging for DNA. Nature 424, 732-734.

5. Hake, S. B., Xiao, A. and Allis, C. D. (2004) Linking the epigenetic 'language' of covalent histone modifications to cancer. $\mathrm{Br}$. J. Cancer 90, 761-769.

6. Seligson, D. B., Horvath, S., Shi, T., Yu, H., Tze, S., Grunstein, M. and Kurdistani, S. K. (2005) Global histone modification patterns predict risk of prostate cancer recurrence. Nature 435, 1262-1266.

7. Lafon-Hughes, L., Di Tomaso, M. V., Mendez-Acuna, L. and Martinez-Lopez, W. (2008) Chromatin-remodelling mechanisms in cancer. Mutat. Res. 658, 191-214.

8. Fanelli, M., Caprodossi, S., Ricci-Vitiani, L., Porcellini, A., Tomassoni-Ardori, F., Amatori, S., Andreoni, F., Magnani, M., De Maria, R., Santoni, A., Minucci, S. and Pelicci, P. G. (2008) Loss of pericentromeric DNA methylation pattern in human glioblastoma is associated with altered DNA methyltransferases expression and involves the stem cell compartment. Oncogene 27, 358-365.

9. Piyathilake, C. J., Frost, A. R., Bell, W. C., Oelschlager, D., Weiss, H., Johanning, G. L., Niveleau, A., Heimburger, D. C. and Grizzle, W. E. (2001) Altered global methylation of DNA: an epigenetic difference in susceptibility for lung cancer is associated with its progression. Hum. Pathol. 32, 856-862.

10. Estecio, M. R., Gharibyan, V., Shen, L., Ibrahim, A. E., Doshi, K., He, R., Jelinek, J., Yang, A. S., Yan, P. S., Huang, T. H., Tajara, E. H. and Issa, J. P. (2007) LINE-1 
Flow Cytometric and Laser Scanning Microscopic Approaches

hypomethylation in cancer is highly variable and inversely correlated with microsatellite instability. PLoS ONE 2, e399.

11. Ogino, S., Kawasaki, T., Nosho, K., Ohnishi, M., Suemoto, Y., Kirkner, G. J. and Fuchs, C. S. (2008) LINE-1 hypomethylation is inversely associated with microsatellite instability and $\mathrm{CpG}$ island methylator phenotype in colorectal cancer. Int. J. Cancer 122, 2767-2773.

12. Shimabukuro, M., Sasaki, T., Imamura, A., Tsujita, T., Fuke, C., Umekage, T., Tochigi, M., Hiramatsu, K., Miyazaki, T., Oda, T., Sugimoto, J., Jinno, Y. and Okazaki, Y. (2007) Global hypomethylation of peripheral leukocyte DNA in male patients with schizophrenia: a potential link between epigenetics and schizophrenia. J. Psychiatr. Res. 41, 1042-1046.

13. Matarazzo, M. R., Boyle, S., D’Esposito, M. and Bickmore, W. A. (2007) Chromosome territory reorganization in a human disease with altered DNA methylation. Proc. Natl. Acad. Sci. U.S.A. 104, 16546-16551.

14. Miranda, T. B. and Jones, P. A. (2007) DNA methylation: the nuts and bolts of repression. J. Cell Physiol. 213, 384-390.

15. Rhee, I., Bachman, K. E., Park, B. H., Jair, K. W., Yen, R. W., Schuebel, K. E., Cui, H., Feinberg, A. P., Lengauer, C., Kinzler, K. W., Baylin, S. B. and Vogelstein, B. (2002) DNMTI and DNMT3b cooperate to silence genes in human cancer cells. Nature 416, 552-556.

16. Sun, L., Zhao, H., Xu, Z., Liu, Q., Liang, Y., Wang, L., Cai, X., Zhang, L., Hu, L., Wang, G. and Zha, X. (2007) Phosphatidylinositol 3-kinase/protein kinase B pathway stabilizes DNA methyltransferase I protein and maintains DNA methylation. Cell Signal 19, 2255-2263.

17. Kuo, M. H. and Allis, C. D. (1999) In vivo cross-linking and immunoprecipitation for studying dynamic protein:DNA associations in a chromatin environment. Methods 19, 425-433.

18. Taylor, J. D., Briley, D., Nguyen, Q., Long, K., Iannone, M. A., Li, M. S., Ye, F., Afshari, A., Lai, E., Wagner, M., Chen, J. and Weiner, M. P. (2001) Flow cytometric platform for high-throughput single nucleotide polymorphism analysis. Biotechniques 30, 661-666, 668-669.

19. Spiro, A. and Lowe, M. (2002) Quantitation of DNA sequences in environmental PCR products by a multiplexed, beadbased method. Appl. Environ. Microbiol. 68, 1010-1013.

20. Bacso, Z., Everson, R. B. and Eliason, J. F. (2000) The DNA of annexin V-binding apoptotic cells is highly fragmented. Cancer Res. 60, 4623-4628.

21. Bacso, Z. and Eliason, J. F. (2001) Measurement of DNA damage associated with apoptosis by laser scanning cytometry. Cytometry 45, 180-186.

22. Khobta, A., Carlo-Stella, C. and Capranico, G. (2004) Specific histone patterns and acetylase/deacetylase activity at the breakpoint-cluster region of the human MLL gene. Cancer Res. 64, 2656-2662.

23. Beck, S. and Rakyan, V. K. (2008) The methylome: approaches for global DNA methylation profiling. Trends Genet. 24, 231-237.

24. Habib, M., Fares, F., Bourgeois, C. A., Bella, C., Bernardino, J., Hernandez-Blazquez, F., de Capoa, A. and Niveleau, A. (1999) DNA global hypomethylation in EBV-transformed interphase nuclei. Exp. Cell Res. 249, 46-53.

25. Adouard, V., Dante, R., Niveleau, A., Delain, E., Revet, B. and Ehrlich, M. (1985) The accessibility of 5-methylcytosine to specific antibodies in doublestranded DNA of Xanthomonas phage XP12. Eur. J. Biochem. 152, 115-121.

26. Gebhard, C., Schwarzfischer, L., Pham, T. H., Andreesen, R., Mackensen, A. and Rehli, M. (2006) Rapid and sensitive detection of CpG-methylation using methyl-binding (MB)-PCR. Nucleic Acids Res. 34, e82.

27. Gebhard, C., Schwarzfischer, L., Pham, T. H., Schilling, E., Klug, M., Andreesen, R. and Rehli, M. (2006) Genome-wide profiling of CpG methylation identifies novel targets of aberrant hypermethylation in myeloid leukemia. Cancer Res. 66, 6118-6128.

28. Schilling, E. and Rehli, M. (2007) Global, comparative analysis of tissue-specific promoter CpG methylation. Genomics 90, 314-323. 